\title{
Hjerneslagbehandling - en tverrspesialisert utfordring
}

\author{
Organiseringen av akutt slagbehandling har i mange år vært en kilde til uenighet, og fortsatt er det store \\ forskjeller mellom norske sykehus. Vi mener det er gode faglige argumenter for å forankre slagmedisin \\ i begge de to spesialitetene nevrologi og geriatri (indremedisin). Vi vil her begrunne dette synet, og samtidig \\ presentere hvordan vi ved Oslo universitetssykehus har organisert slagbehandlingen.
}

Det representerte et gjennombrudd i hjerneslagbehandlingen da man for 20 år siden $\mathrm{i}$ en randomisert undersøkelse fra Trondheim kunne vise at behandling $i$ en spesialisert slagenhet fører til bedre overlevelse og bedre funksjonelt resultat sammenliknet med behandling i vanlig sengepost (1). Senere er dette funnet bekreftet $i$ en rekke studier fra ulike deler av verden (2). Effekten er betydelig. Det er beregnet at for 20 pasienter som behandles i slagenhet $\mathrm{i}$ stedet for alternative modeller oppnås én ekstra pasient som overlever og blir uavhengig av hjelp i dagliglivet (3). Behandlingsprinsippet er nyttig for praktisk talt alle undergrupper av slagpasienter, uavhengig av alder, underliggende årsak og øvrig behandling (4). Det er tankevekkende at slagenhetskonseptet ble utviklet i en tid da teknologiske nyvinninger som trombolytisk behandling og magnetisk resonanstomografi (MR) bare var fremtidsdrømmer - selv computertomografi (CT) av hjernen var lite tilgjengelig utenom vanlig arbeidstid. Internasjonale retningslinjer definerer hva som hører med i et komplett slagsenter, og det legges meget stor vekt på at en effektiv organisering av alle nødvendige komponenter er helt avgjørende (5):

- Grundig diagnostisk avklaring

- Rask oppstart av reperfusjonsbehandling

- Målrettet sekundærprofylakse

- Optimalisering av generell fysiologisk homøostase, komorbide tilstander og samlet legemiddelbehandling

- Umiddelbar oppstart av mobilisering og rehabilitering integrert med akuttbehandlingen

- Aktiv forebygging og bekjempelse av komplikasjoner

- Bruk av et godt koordinert tverrfaglig team

- Tidlig utskrivningsplanlegging $(6,7)$

Det er grunn til å merke seg at alle elementene ovenfor må være med i en godt koordinert helhet for å gi effekt. Oppbygging av en effektiv slagenhet er derfor en møysommelig og tidkrevende organisatorisk utfordring. Det er aldri dokumentert effekt av slagenheter for ren akutt- eller intensivbehandling som ikke samtidig inneholder elementer av rehabilitering, og heller ikke av slagenheter med kortere liggetid enn om lag en uke (2).

\section{Nye behandlingsmetoder, nye utfordringer}

De senere årene har hyperakutt reperfusjonsbehandling fått økende aktualitet for pasienter med hjerneslag. Standard reperfusjonsbehandling er intravenøs alteplase (rekombinant vevstromboplastinaktivator), men kateterbasert intraarteriell behandling (trombektomi, blokking og/eller intraarteriell trombolytisk behandling) ser ut til å få raskt økende betydning.

Ifølge europeiske retningslinjer kan intravenøs trombolytisk behandling gis inntil 4,5 timer etter iskemisk hjerneslag (5). Ved kateterbasert intraarteriell behandling er tidsvinduet som regel angitt til 6-8 timer i fremre kretsløp og enda lengre i bakre kretsløp. I en samleanalyse av publiserte, randomiserte studier av intravenøs trombolytisk behandling fant man at ved behandling innen tre timer oppnådde drøyt $40 \%$ av pasientene en skår på 0 eller 1 på den modifiserte Rankin-skalaen (8) etter tre måneder, hvilket innebærer intet eller minimalt sekvele (9). I placebogruppen var det om lag 30\% som oppnådde et tilsvarende resultat. Effekten av trombolysebehandling på dødeligheten er fortsatt usikker (10).

Tiden spiller en viktig rolle ved hyperakutt reperfusjonsbehandling. Antall pasienter som må behandles for at én skal få et utmerket behandlingsresultat som kan tilskrives intravenøs trombolyse, er fem i tidsintervallet opp til 1,5 timer, ni i tidsintervallet 1,5-3 timer og 15 i tidsintervallet 3-4,5 timer (9). Det er rimelig å tro at også intraarteriell behandling resulterer i større effekt jo tidligere i sykdomsforløpet den igangsettes. Derfor er det svært viktig å organisere prehospital vurdering og transport samt den initiale sykehusbehandlingen slik at hyperakutt reperfusjonsbehandling tilbys raskest mulig til alle som kan ha nytte av den. Behandlingen må baseres på en presis klinisk og radiologisk diagnostikk og hviler derfor tungt på nevrologisk og nevroradiologisk kompetanse.

På grunn av kort tidsvindu og en rekke kontraindikasjoner er hyperakutt reperfusjonsbehandling fortsatt ikke aktuelt for et flertall av pasientene. Ved slagsentre som har satset maksimalt på reperfusjonsbehandling, inkludert optimalisert prehospital logistikk, er man kommet opp i en andel på ca. $20 \%$ av slagpasientene som tilbys slik behandling (11). Noen opplever meget gode behandlingsresultater, andre pasienter responderer mindre eller har ingen respons. Det er derfor på ingen måte slik at moderne reperfusjonsbehandling gjør annen akutt slagbehandling uaktuell eller unødvendig. Tvert imot, for flertallet av pasientene gir de øvrige komponentene i slagenhetsbehandlingen større gevinster enn reperfusjonsbehandlingen (3).

\section{Organisatoriske konsekvenser}

Slagenheter bør etter vår mening organiseres ut fra hva som gir optimal pasientbehandling, ikke nødvendigvis etter tradisjonelle medisinske spesialiteter.

Hyperakutt reperfusjonsbehandling krever nevrologisk og nevroradiologisk kompetanse. Videre er nevrologisk kompetanse nødvendig for patofysiologisk og nevrovaskulær diagnostikk som danner grunnlag for målrettet sekundærprofylakse. Nevrologen har også ansvar for grensegangen mot nevrologiske differensialdiagnoser.

Samtidig har flere av slagenhetsprinsippene svært mye til felles med den geriatriske arbeidsmetoden, der man vektlegger omfattende kartlegging av relevante bidiagnoser, aktiv forebygging av komplikasjoner, tidlig mobilisering og rehabilitering, koordinert tverrfaglig samarbeid samt tidlig planlegging av utskrivningen (6). I tillegg har mange pasienter med akutt hjerneslag også indremedisinske tilstander som hypertensjon, diabetes, hyperkolesterolemi, koronarsykdom, kronisk obstruktiv lungesykdom og hjertesvikt, sykdommer som geriatere er trent $\mathrm{i}$ å håndtere. Det foreligger også en rekke indremedisinske og geriatriske differensialdiagnoser. Derfor har det vært naturlig at geriatere ved mange sykehus har tatt hånd om slagbehandlingen. Men gode slagenheter er etablert både innenfor rammen av nevrologiske, geriatriske og generelle indremedisinske avdelinger.

Det er to grøfter å falle i. Slagenheter med stor vekt på rehabilitering og generell medisinsk behandling kan få for svakt fokus på akutt reperfusjon og de betydelige logistiske og medisinske utfordringene som må overvinnes for å gi reperfusjonsbehandling raskest mulig til flest mulig. De kan også bli svake på nevrovaskulær utredning. Slagenheter som ensidig vektlegger reperfusjonsbehandling risikerer på den annen 


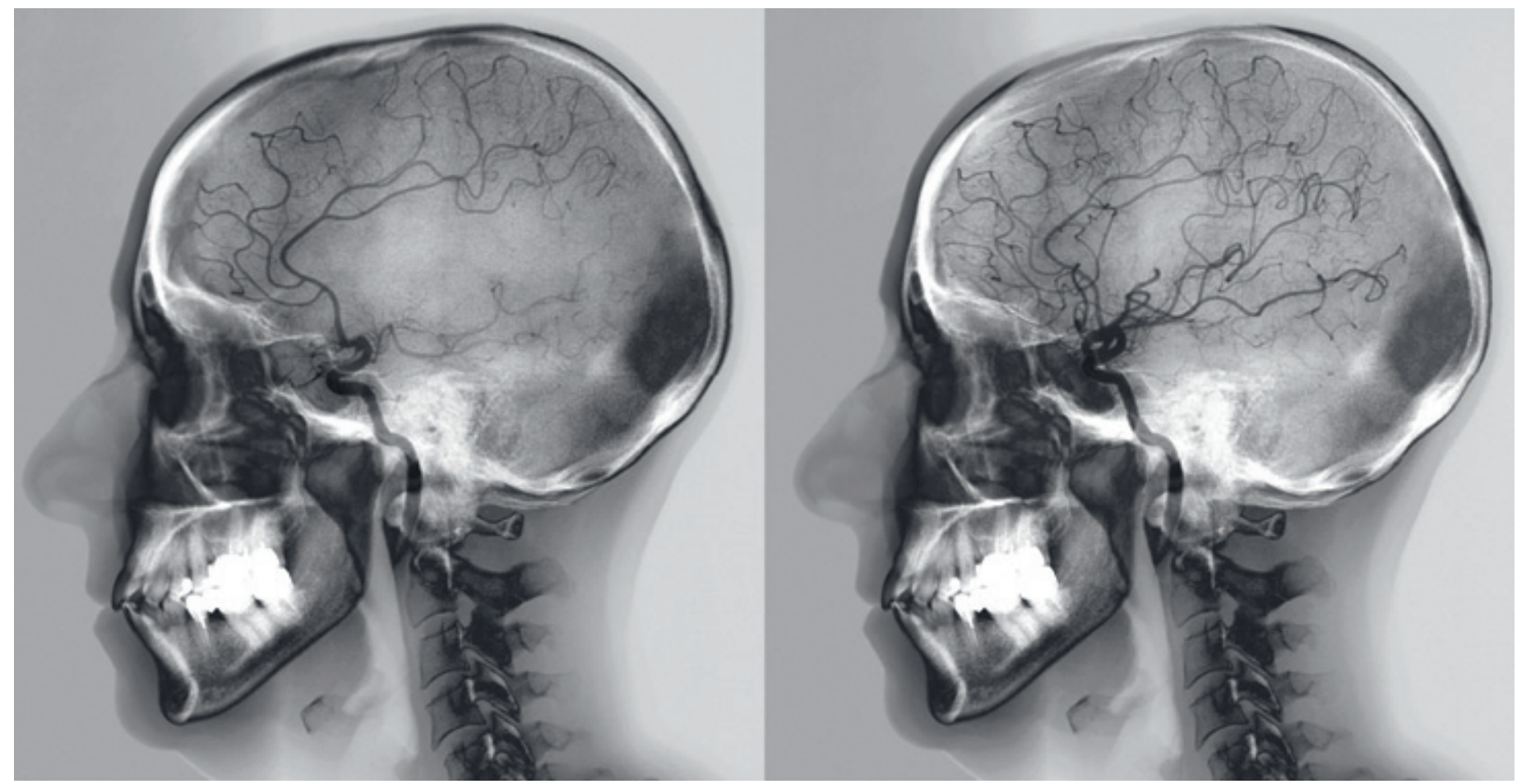

Intrakranial sirkulasjon før og etter revaskularisering. Illustrasjonsfoto Sciencephoto/SCANPIX

side å forsømme de øvrige meget virksomme behandlingselementene. Målet må naturligvis være å tilby pasientene en optimal behandlingspakke der alle potensielt nyttige behandlinger utnyttes fullt ut og er godt koordinert. Spesialitetene nevrologi og geriatri (som også omfatter generell indremedisin) representerer i denne sammenhengen komplementær kompetanse av særskilt nytte. Dette synet samsvarer godt med britisk praksis, der «stroke medicine» er et etablert fagfelt særlig forankret i nevrologi og geriatri (12).

Tilsvarende bred kompetanse er nødvendig blant sykepleierne. Moderne intervensjonelle teknikker krever en presis hjerneovervåkning. Dette innebærer tett og standardisert monitorering av nevrologisk status med f.eks. National Institutes of Health Stroke Scale (NIHSS), grundig monitorering av vitale funksjoner og klare rutiner for tiltak ved forverring eller avvik. Samtidig må sykepleierne ha omfattende kunnskaper og ferdigheter i rehabiliterende sykepleie, hvilket innebærer at alt som skjer med pasienten gjennom døgnet - fra dag én - skal ha et rehabiliterende siktemål.

I tillegg til dette må slagenheten naturligvis ha den nødvendige tverrfaglige bemanning av fysioterapeuter, ergoterapeuter, logopeder, sosionom, ernæringsfysiolog og nevropsykolog, inkludert en effektiv struktur for kommunikasjon og samarbeid yrkesgruppene imellom.

\section{Erfaringer fra \\ Oslo universitetssykehus}

Daværende Ullevål universitetssykehus reorganiserte sin hjerneslagbehandling i 2007. En internasjonalt ledet evalueringsgruppe beskrev høsten 2010 den valgte modellen som god og fremtidsrettet, og anbefalte at den må legges til grunn for den fremtidige slagbehandlingen ved Oslo universitetssykehus (13).

Alle pasienter med mistenkt akutt hjerneslag meldes initialt til nevrologisk vaktteam. Vakthavende nevrolog sikrer optimal diagnostikk og igangsetter akutt behandling, herunder reperfusjonsbehandling, i nært samarbeid med vakthavende nevroradiolog. Unntak kan gjøres for pasienter som åpenbart ikke er aktuelle for reperfusjonsbehandling; disse kan eventuelt tas imot av vakthavende indremedisiner, slik at de to vaktteamenes samlede kapasitet blir optimalt utnyttet. De fleste får likevel tilsyn av nevrolog før journalskriving. Alle pasienter med mistenkt transitorisk iskemisk anfall (TIA), hjerneinfarkt eller hjerneblødning, uansett alder, legges inn i Seksjon for hjerneslag, som er en seksjon i Geriatrisk avdeling, men er bemannet både med nevrologer og geriatere/indremedisinere. Det nevrologiske vaktteamet beholder det medisinske ansvaret for pasientene frem til morgenen etter innleggelsen, da ansvaret overtas av den tverrfaglige legegruppen ved Seksjon for hjerneslag. Ved behov for legetilsyn utenom ordinær arbeidstid senere i forløpet ligger ansvaret på det indremedisinske/geriatriske vaktteamet. Dette er hensiktsmessig, siden akutt forverring i den subakutte fasen som regel skyldes indremedisinske/geriatriske komplikasjoner som infeksjoner, hjerte- og karhendelser, delirium og tromboemboliske tilstander. Nevrologisk vaktlag tilkalles ved behov.
Ved seksjonen har det siden oppstarten foregått et systematisk og omfattende arbeid for videreutdanning av leger og sykepleiere. Den første tiden foregikk intravenøs trombolytisk behandling ved overvåkingsavdelingen, men fra mai 2009 er dette gjort i slagenheten. Etter opplæring blir seksjonens sykepleiere autorisert som trombolysesykepleiere. Når en pasient skal ha reperfusjonsbehandling, rykker trombolyseansvarlig sykepleier ut fra Seksjon for hjerneslag til Akuttmottaket og bistår vakthavende nevrolog. Infusjonen påbegynnes i Akuttmottaket og kontinueres under transport til slagenheten. Sykepleier bistår med hjerneovervåking i form av repeterte skåringer av NIHSS og Glascow Coma Scale samt tett monitorering av blodtrykk, puls/ EKG, oksygenmetning, temperatur og blodsukker. Trombolysesykepleier overvåker pasientene også under transport til eventuell intraarteriell intervensjon, som inntil november 2010 foregikk ved Oslo universitetssykehus, Ullevål, senere ved Oslo universitetssykehus, Rikshospitalet.

I den videre utredningen legges det vekt på både etiologisk og topografisk diagnostikk i henhold til TOAST-klassifikasjonen (14) og Oxford-kriteriene (15). I tillegg til en klinisk nevrologisk vurdering brukes ultralydundersøkelse av precerebrale og intracerebrale arterier, CT- og MR-undersøkelser, og ved behov nevrofysiologiske undersøkelser. Alle pasienter som er innlagt med TIA, hjerneinfarkt eller hjerneblødning gjennomgår en omfattende og standardisert funksjonell kartlegging som grunnlag for en målrettet rehabilitering, basert på vurderinger av fysioterapeut, ergoterapeut, 
logoped, sosionom og slagsykepleier. Alle pasienter blir skåret med NIHSS, Barthel ADL-indeks, Rankin-skalaen (8), Mini Mental Status Evaluering (MMSE), klokketest, Trail Making Test A og B og Ullevål afasiscreening. Andre skåringsverktøy brukes ved behov. Alle pasienter blir vurdert på tverrfaglige behandlingsmøter som holdes to ganger i uken.

Siden starten i 2007 har slagenheten behandlet $600-650$ pasienter med akutt cerebrovaskulær sykdom per år (hjerneinfarkter, intracerebrale blødninger og transitoriske iskemiske anfall). Andelen pasienter som får hyperakutt reperfusjonsbehandling har i denne perioden økt fra under $5 \%$ til drøyt $20 \%$ av pasientene med iskemisk hjerneslag. Noe av økningen kan skyldes at sykehuset nå får en høyere andel pasienter som er aktuelle for trombolytisk behandling fra andre sykehusområder, men vi mener hovedårsaken er bedret logistikk internt i sykehuset, slik at flere pasienter blir vurdert i tide. Spesielt så vi en markert $ø$ kning i trombolyseandelen kombinert med en reduksjon i tidsintervallet fra ankomst sykehuset til oppstart av trombolytisk behandling i forbindelse med etablering av ordningen med trombolysesykepleier og trombolytisk behandling i slagenheten i mai 2009.

\section{Utfordringer}

Ullevål-modellen for organisering av slagbehandling er ukonvensjonell. Av historiske grunner har sykehuset $\mathrm{i}$ mange år hatt sterke fagmiljøer både i nevrologisk, geriatrisk og andre medisinske avdelinger som jobbet parallelt med ulike grupper av slagpasienter, og til dels med samme pasienter i ulike sykdomsfaser. Nåværende Seksjon for hjerneslag tok form i forbindelse med en omfattende omorganisering, og konseptet ble utarbeidet av en arbeidsgruppe med bred forankring i både indremedisinsk/ geriatrisk og nevrologisk miljø og involverte alle relevante yrkesgrupper. Det overordnede målet var å tilby best mulig pasientbehandling for det store antallet slagpasienter sykehuset tar imot, og å etablere en gjennomgående behandlingskjede fra mottak til utskrivning for alle slagpasienter uansett alder eller bosted. Pasientene skulle ivaretas av ett og samme behandlingsteam fra innleggelsen og gjennom hele akuttfasen (i snitt 8-10 dager).

Organisering av akuttbehandling på tvers av medisinske spesialiteter, klinikker og divisjoner er krevende og forutsetter stor grad av gjensidig respekt for hverandres kompetanse. Etableringen av Oslo universitetssykehus med sine geografisk adskilte behandlingssteder har medført ytterligere utfordringer. I november 2010 ble den gjennomgående behandlingskjeden dessverre brutt for pasienter som skal ha intraarteriell reperfusjonsbehandling, ved at denne behandlingen ble flyttet fra Ullevål til Rikshospitalet mens den øvrige kliniske hjerneslagbehandlingen ble værende på Ullevål. Indikasjonen for intraarteriell behandling er basert på nevroradiologiske kriterier og må vurderes i sykehuset. Pasienter som skal ha intraarteriell behandling undersøkes derfor først på Ullevål før de må sendes videre med ambulanse. Disse får derfor en betydelig forsinkelse i oppstart av behandling. For de øvrige slagpasientene tilbys fortsatt en sammenhengende og tverrspesialisert behandlingslinje, samlet på én geografisk enhet.

\section{Konklusjon}

Våre erfaringer med slagbehandling forankret i spesialitetene nevrologi og geriatri er gode. Vi opplever tverrfagligheten som fordelaktig for pasientene og samtidig inspirerende og lærerik for personalet. Dessuten gir samling av fagmiljøet store muligheter for forskning og fagutvikling. Slagmedisin er verken geriatri, indremedisin eller nevrologi alene, men snarere en syntese av disse fagområdene. Selv om de ulike spesialitetene er sterkest involvert i litt ulike faser av behandlingsforløpet, synes vi at pasientene er best tjent med en reell tverrfaglighet $i$ alle faser fremfor en oppdelt ordning der f.eks. akuttbehandlingen er nevrologisk og rehabiliteringen geriatrisk, eller yngre pasienter nevrologiske og eldre geriatriske. Fasen preget av revirkamp i norsk slagmedisin bør være forbi. Pasientene fortjener bedre.

\section{Antje Reichenbach* \\ Elisabeth Gulowsen Celius \\ Nevrologisk avdeling \\ Brynjar Fure** \\ Sigurd Vatn \\ Torgeir Bruun Wyller \\ t.b.wyller@medisin.uio.no \\ Geriatrisk avdeling}

Oslo universitetssykehus

* Nåværende adresse:

Nevroklinikken

Akershus universitetssykehus

** Nåværende adresse:

Nasjonalt kunnskapssenter for helsetjenesten

Antje Reichenbach (f. 1968) er spesialist i nevrologi og overlege ved Nevroklinikken, Akershus universitetssykehus. Hun har mer enn 15 års erfaring med akuttbehandling og rehabilitering av slagpasienter ved ulike slagsentre. Ingen oppgitte interessekonflikter.

Elisabeth Gulowsen Celius (f. 1961) er dr.med. og spesialist i nevrologi. Hun er seksjonsleder i Nevrologisk avdeling, og jobber klinisk og forskningsmessig hovedsaklig med multippel sklerose. Ingen oppgitte interessekonflikter.
Brynjar Fure (f. 1959) er dr.med, spesialist i nevrologi og indremedisin/geriatri. Han jobber som forskningsleder ved Seksjon for spesialisthelsetjenesten, Nasjonalt kunnskapssenter for helsetjenesten og som overlege ved Seksjon for hjerneslag. Ingen oppgitte interessekonflikter.

Sigurd Vatn (f.1951) er spesialist indremedisin/ geriatri og er seksjonsleder ved Slagenheten, Geriatrisk avdeling. Ingen oppgitte interessekonflikter.

Torgeir Bruun Wyller (f. 1960) er spesialist $\mathrm{i}$ indermedisin/geriatri. Han er overlege og professor i geriatri ved Universitetet i Oslo. Ingen oppgitte interessekonflikter.

\section{Litteratur}

1. Indredavik B, Bakke F, Solberg R et al. Benefit of a stroke unit: a randomized controlled trial. Stroke 1991: 22: $1026-31$.

2. Stroke Unit Trialists' Collaboration. Organised inpatient (stroke unit) care for stroke. Cochrane Database Syst Rev 2007; nr. 4: CD000197.

3. Langhorne P. Sandercock P. Prasad K. Evidencebased practice for stroke. Lancet Neurol 2009; 8: 308-9.

4. Stroke Unit Trialists' Collaboration. Collaborative systematic review of the randomised trials of organised inpatient (stroke unit) care after stroke. BM 1997: 314: 1151 -9.

5. Guidelines for management of ischaemic stroke and transient ischaemic attack 2008. Cerebrovasc Dis 2008; 25: 457-507

6. Stroke Unit Trialists' Collaboration. How do stroke units improve patient outcomes? A collaborative systematic review of randomized trials. Stroke 1997; 28: 2139-44.

7. Govan L, Langhorne P. Weir CJ. Does the prevention of complications explain the survival benefit of organized inpatient (stroke unit) care?: further analysis of a systematic review. Stroke 2007; 38 : $2536-40$

8. Sulter G. Steen C. De Keyser J. Use of the Barthe Index and modified Rankin Scale in acute stroke trials. Stroke 1999; 30: 1538-41

9. Lees KR, Bluhmki $\mathrm{E}$, von Kummer $\mathrm{R}$ et al. Time to treatment with intravenous alteplase and outcome in stroke: an updated pooled analysis of ECASS, ATLANTIS, NINDS, and EPITHET trials. Lancet 2010; 375: 1695-703.

10. Wardlaw JM, Murray V, Berge E et al. Thrombolysis for acute ischaemic stroke. Cochrane Database Syst Rev 2009; nr. 4: CD000213.

11. Wojner-Alexandrov AW, Alexandrov AV, Rodriguez $D$ et al. Houston paramedic and emergency stroke treatment and outcomes study (HoPSTO). Stroke 2005: 36: 1512-8

12. British Association of Stroke Physicians. www.basp.ac.uk (22.1.2011).

13. Persson L, Frich J, Antonsen $\emptyset$ et al. Organisering av behandlingstilbudet til pasienter med hjerneslag ved Oslo universitetssykehus. Anbefalinger fra en arbeidsgruppe høsten 2010. Oslo: Oslo universitetssykehus, 2010.

14. TOAST Investigators. Low molecular weight heparinooid, ORG 10172 (Danaparoid), and outcome after acute ischemic stroke. JAMA 1998; 279: $1265-72$

15. Bamford J, Sandercock P, Dennis M et al. A prospective study of acute cerebrovascular disease in the community: the Oxfordshire Community Stroke Project - 1981-86. J Neurol Neurosurg Psychiatry 1990; 53: 16-22. 